\title{
Mechanical Behavior of Nanostructured Hybrids Based on Poly(Vinyl Alcohol)/Bioactive Glass Reinforced with Functionalized Carbon Nanotubes
}

\author{
H. S. Mansur, ${ }^{1}$ M. M. Pereira, ${ }^{1}$ H. S. Costa, ${ }^{2}$ and A. A. P. Mansur ${ }^{1}$ \\ ${ }^{1}$ Center of Nanoscience, Nanotechnology, and Innovation (CeNano) and Department of Metallurgical and Materials Engineering, \\ Federal University of Minas Gerais, 31270-901 Belo Horizonte, MG, Brazil \\ ${ }^{2}$ Department of Metallurgy and Material Engineering, Centro Federal de Educação Tecnológica de Minas Gerais, \\ Avenida Amazonas 5253, Nova Suiça, 30421-169 Belo Horizonte, MG, Brazil \\ Correspondence should be addressed to H. S. Mansur, hmansur@demet.ufmg.br
}

Received 21 August 2012; Revised 26 October 2012; Accepted 6 November 2012

Academic Editor: Tianxi Liu

Copyright () 2012 H. S. Mansur et al. This is an open access article distributed under the Creative Commons Attribution License, which permits unrestricted use, distribution, and reproduction in any medium, provided the original work is properly cited.

This study reports the synthesis and characterization of novel tridimensional porous hybrids based on PVA combined with bioactive glass and reinforced by chemically functionalized carbon nanotubes (CNT) for potential use in bone tissue engineering. The functionalization of CNT was performed by introducing carboxylic groups in multiwall nanotubes. This process aimed at enhancing the affinity of CNTs with the water-soluble PVA polymer derived by the hydrogen bonds formed among alcohol (PVA) and carboxylic groups (CNT-COOH). In the sequence, the CNT-COOH $(0.25 \mathrm{wt} \%)$ were used as the nanostructure modifier for the hybrid system based on PVA associated with the bioactive glass $(\mathrm{BaG})$. The mechanical properties of the nanostructured hybrids reinforced with CNT-COOH were evaluated by axial compression tests, and they were compared to reference hybrid. The averaged yield stresses of macroporous hybrids were $(2.3 \pm 0.9)$ and $(4.4 \pm 1.0) \mathrm{MPa}$ for the reference and the CNT reinforced materials, respectively. Moreover, yield strain and Young's modulus were significantly enhanced by about $30 \%$ for the $\mathrm{CNT}-\mathrm{COOH}$ hybrids. Hence, as far as the mechanical properties are concerned, the results have clearly showed the feasibility of utilizing these new hybrids reinforced with functionalized CNT in repairing cancellous bone tissues.

\section{Introduction}

Despite the fact that materials science technology has resulted in clear improvements in the field of bone substitution medicine, no satisfactory bone substitute has been developed yet. As a result, most of the severe injuries related to bone are still unrecoverable or not adequately treated [ 1 , 2]. Regeneration of tissue using the body's own self-healing mechanisms is an ideal approach for bone repair, which is the aim of tissue engineering, that is, to restore diseased or damaged tissue to its original state and function, reducing the need for transplants and replacements. More specifically, bone tissue engineering combines cells and a biodegradable $3 \mathrm{D}$ scaffold to repair bone tissue. One of the challenges in tissue engineering is associated with the development of suitable scaffold materials that can act as templates for cell adhesion, growth, and proliferation.
Bioactive glasses are important bioceramic materials and have been used for the repair and reconstruction of diseased bone tissues. Nevertheless, bioactive glasses usually have reduced mechanical properties, especially in a porous form, compared to cortical and cancellous bone. The alternative that is being considered is the development of novel composites materials and hybrid systems. In the last 3 decades, several research groups have developed a variety of biomaterials to act as synthetic scaffolds that may guide and stimulate the three-dimensional tissue growth [3-11].

Our group has been active on researching the synthesis and characterization of organic-inorganic hybrids in the system poly(vinyl alcohol)/bioactive glass ( $\mathrm{PVA} / \mathrm{BaG})[12-$ 15] to be used as scaffolds in tissue engineering applications. $\mathrm{PVA} / \mathrm{BaG}$ have been prepared by the sol-gel process and the effect of PVA content, degree of hydrolysis, and synthesis conditions on properties of the porous scaffolds, 
and on degradation kinetics have been reported [16-19]. The results have clearly shown that it is possible to tailor the hybrids mechanical properties and degradation behavior by engineering the structure of the materials. Nevertheless, the level of mechanical strength attained can be still improved by further nanostructure control and use of additional strengthening mechanisms.

Carbon nanotubes (CNTs) have been used as reinforcement of polymers due to their extremely high strength to weight ratio, with superior mechanical properties. However, it is known that the efficiency of CNTs as polymer reinforcements will depend on their chemical affinity to polymer, which may affect their dispersion in the polymeric phase, and the polymer matrix/CNT interface bonding [20].

Chemical functionalization of CNT is an effective way for preventing aggregation and allowing dispersion and stabilization in the polymer matrix. Among the several studied methods, covalent functionalization can be highlighted [21]. In general, functional $\mathrm{COOH}$ or $\mathrm{OH}$ groups can be created on CNT surface by oxidation with oxygen, air, sulfuric acid, nitric acid, or mixtures of acids [22, 23].

An increase in the amount of methods available for chemical modification and functionalization of CNTs has made possible their dispersion in water and allowed manipulation and processing in physiological environment [24, 25]. The functionalization of CNTs with carboxylic acid groups is convenient since a variety of reactions can be carried out with this chemical group [26].

Thus, to the best of our knowledge, this is the first report to synthesize and characterize novel macroporous bionanocomposite scaffolds designed by combining polymer (PVA) with bioactive glass (BaG) and reinforced with chemically modified carbon nanotubes. These hybrids were produced based on the reaction of the organic and inorganic precursors using the foaming method via sol-gel route and then reinforced by functionalized carbon nanotubes. The mechanical properties of the hybrids were evaluated by compression tests, and the results were analyzed considering the cancellous bone as the target promising application.

\section{Materials and Methods}

2.1. Synthesis of CNT Reinforced Hybrid Scaffolds. To avoid redundancy with previous researches published by our group $[18,19]$, the full details for the synthesis and characterization of the hybrids based on PVA and bioactive glass were not included in this study. Here, the major focus was given to the novelty associated with the effect on the mechanical properties by adding the chemically modified carbon nanotubes to the macroporous hybrid nanostructures. So, poly(vinyl alcohol)/bioactive glass $(\mathrm{BaG})$ hybrid scaffolds reinforced with carbon nanotubes (CNTs) were prepared by a sol-gel foaming method, and three hybrid systems were produced: (i) hybrid with composition $70 \mathrm{wt} . \%$ polymer and $30 \mathrm{wt} . \%$ glass (PVA/BaG); (ii) hybrid with same composition, cross linked with 5\% glutaraldehyde (PVA/BaG/GA); (iii) hybrid with same composition, with addition of functionalized CNT (PVA/BaG/CNT).
Purified multiwall CNTs, with 10 to $30 \mathrm{~nm}$ external diameter, and 1 to $2 \mu \mathrm{m}$ length, from SES Research (USA), were functionalized with carboxylic groups before use. The chemical modification was performed by refluxing $1.0 \mathrm{~g}$ of CNT's in $50 \mathrm{~mL} \mathrm{HNO}_{3} 14 \mathrm{~mol} \cdot \mathrm{L}^{-1}$ for $15 \mathrm{~h}$ at $120^{\circ} \mathrm{C}$, followed by filtration using $0.7 \mu \mathrm{m}$ filter (AP4004700-Millipore). CNTs were then washed with DI water, until filtrate reached $\mathrm{pH}$ $5.5 \pm 0.1$ and dried for 48 hours at $60 \pm 5^{\circ} \mathrm{C}$.

PVA aqueous solution with concentration $28 \mathrm{wt} \% \%$ was prepared by dissolving PVA powder (Aldrich-Sigma with degree of hydrolysis $\mathrm{DH}=80 \%$ and molecular weight $\mathrm{Mw}=$ $9,000-10,000 \mathrm{~g} / \mathrm{mol}$ ) in a water bath at $90^{\circ} \mathrm{C}$ under constant stirring, for $1 \mathrm{~h}$. The $\mathrm{pH}$ of the solution was corrected to $2.0 \pm 0.1$ with hydrochloric acid $(\mathrm{HCl})$ solution $2 \mathrm{~N}$. For preparation of the reinforced hybrids, appropriate amount of CNT was added to the PVA solution, in a proportion of 0.25 wt. (\%) with respect to PVA.

The starting sol solution with designed composition 58 wt.\% $\quad \mathrm{SiO}_{2}-33$ wt.\% $\mathrm{CaO}-9$ wt.\% $\quad \mathrm{P}_{2} \mathrm{O}_{5}$ was synthesized by mixing tetraethoxysilane (TEOS), DI water, triethylphosphate (TEP), and calcium chloride in presence of hydrofluoric acid solution $2 \mathrm{~N}$. The water/alkoxide molar ratio used for was $12: 1\left(\mathrm{H}_{2} \mathrm{O}:\right.$ TEOS $)$.

An appropriate amount of the glass precursor sol was added to the PVA solution, with and without CNTs added, and the mixture was stirred for approximately five minutes. Then, a surfactant sodium laureate sulfate (SLS, Oxiteno $27 \% \mathrm{v} / \mathrm{v}$ ) and a catalyst ( $\mathrm{HF} 10 \% \mathrm{v} / \mathrm{v}$ ) were added as foaming and gelling agents, respectively. The mixture was vigorously stirred, and the foams obtained were cast just before gelation in plastic containers, which were then sealed. All samples were aged and dried for 10 days at $40^{\circ} \mathrm{C}$. Glutaraldehyde (GA, Sigma 25 wt.\% aqueous solution, IUPAC: Pentane-1,5dial) was added as bifunctional chemical modifier for the preparation of the cross-linked hybrids, in a concentration of 1.0 wt. $\%$ with respect to PVA.

\subsection{Structural and Mechanical Characterization of Hybrids.} For the evaluation of pore morphology and macropore size range, SEM images were taken from organic-inorganic hybrids with a JSM 6360LV (JEOL/NORAN) microscope. Prior to examination, samples were coated with a thin gold film by sputtering. Secondary electrons (SE) images were obtained by using an accelerating voltage of $10-15 \mathrm{kV}$. CNTs images were assessed using TEM (Tecnai G2-Spirit-FEI) at $120 \mathrm{kV}$. The samples were by placed onto a holey carbon grid for the TEM analysis.

FTIR spectra were obtained within the range 600$4000 \mathrm{~cm}^{-1}$ (Perkin-Elmer, Paragon 1000), using the attenuated total reflectance spectroscopy method (ATR-FTIR). Hybrid samples were placed on the ATR crystal prism $(\mathrm{ZnSe})$, and 64 scans were acquired at $2 \mathrm{~cm}^{-1}$ resolution with the subtraction of background.

The mechanical behavior of the hybrids was evaluated by compression tests. Specimens were evenly cut from the most homogeneous region of the strut to form cubic blocks (approximately $10 \times 10 \times 10 \mathrm{~mm}^{3}$ ) and tested using equipment EMIC DL 3000, with a crosshead speed of $0.5 \mathrm{~mm} \cdot \mathrm{min}^{-1}$ and a $2.0 \mathrm{kN}$ load cell. At least five replicates 


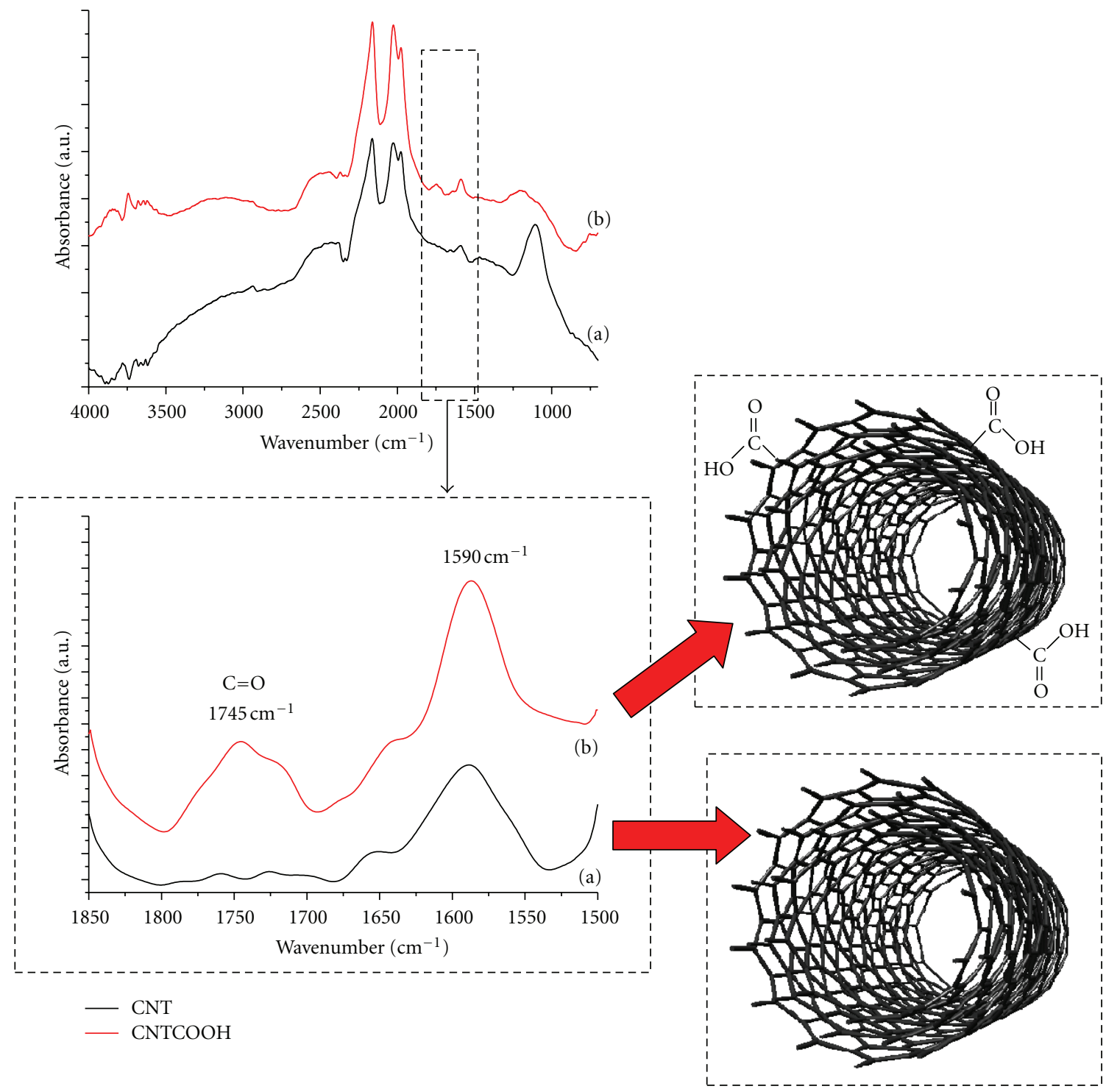

FIGURE 1: FTIR spectra of (a) CNT and (b) CNT functionalized by chemical treatment. Bellow the magnified spectra from $1850-1500 \mathrm{~cm}^{-1}$. Inset: structures of CNT before and after carboxylic functionalization $(\mathrm{CNT}-\mathrm{COOH})$.

$(n=5)$ of each hybrid system were measured, and the results averaged.

\section{Results and Discussion}

Several works in the literature show that carboxylic groupsmodified CNTs (CNT-COOH) are very efficient as reinforcing agents in composites. In this work a treatment with $\mathrm{HNO}_{3}$ was used to functionalize CNT with carboxylic groups. Figure 1 presents the FTIR spectra of CNT before and after the chemical treatment. In the modified CNT spectrum a band at $1745 \mathrm{~cm}^{-1}$ can be observed which corresponds to the stretching vibration of carboxyl groups $(-\mathrm{COOH})$ introduced. This result shows that the chemical treatment used was effective to functionalize the CNTs, allowing a good dispersion of CNT's in the PVA solution and their incorporation into the composite scaffold.
In Figure 2 it presents a set of images (from Figure 2(a) to Figure $2(\mathrm{~h})$ ) obtained for hybrids made of PVA/BaG (Figures 2(a) and 2(c)) and PVA/BaG modified with CNT-COOH (Figures 2(b), 2(d), 2(e), 2(f), 2(g), and $2(\mathrm{~h})$ ). Preliminarily, the visual analysis (digital images, no magnification) has indicated that homogeneous systems were synthesized (Figures 2(a) and 2(b), BaG/PVA and PVA/BaG/CNT-COOH, resp.). It is worth noting that a remarkable color change to "black" was observed in $\mathrm{BaG} / \mathrm{PVA} / \mathrm{CNT}-\mathrm{COOH}$ samples as compared to "white" PVA/BAG hybrids due to the CNTs incorporated into the structure but with a uniform and relatively even distribution in the material. The SEM images of the hybrids with CNTs reinforcement (Figure 2(d)) have showed that threedimensional macropore structures were produced similar to the hybrids without CNTs (Figure 2(c)). Moreover, SEM images of PVA/BaG modified with $\mathrm{CNT}-\mathrm{COOH}$ at higher 


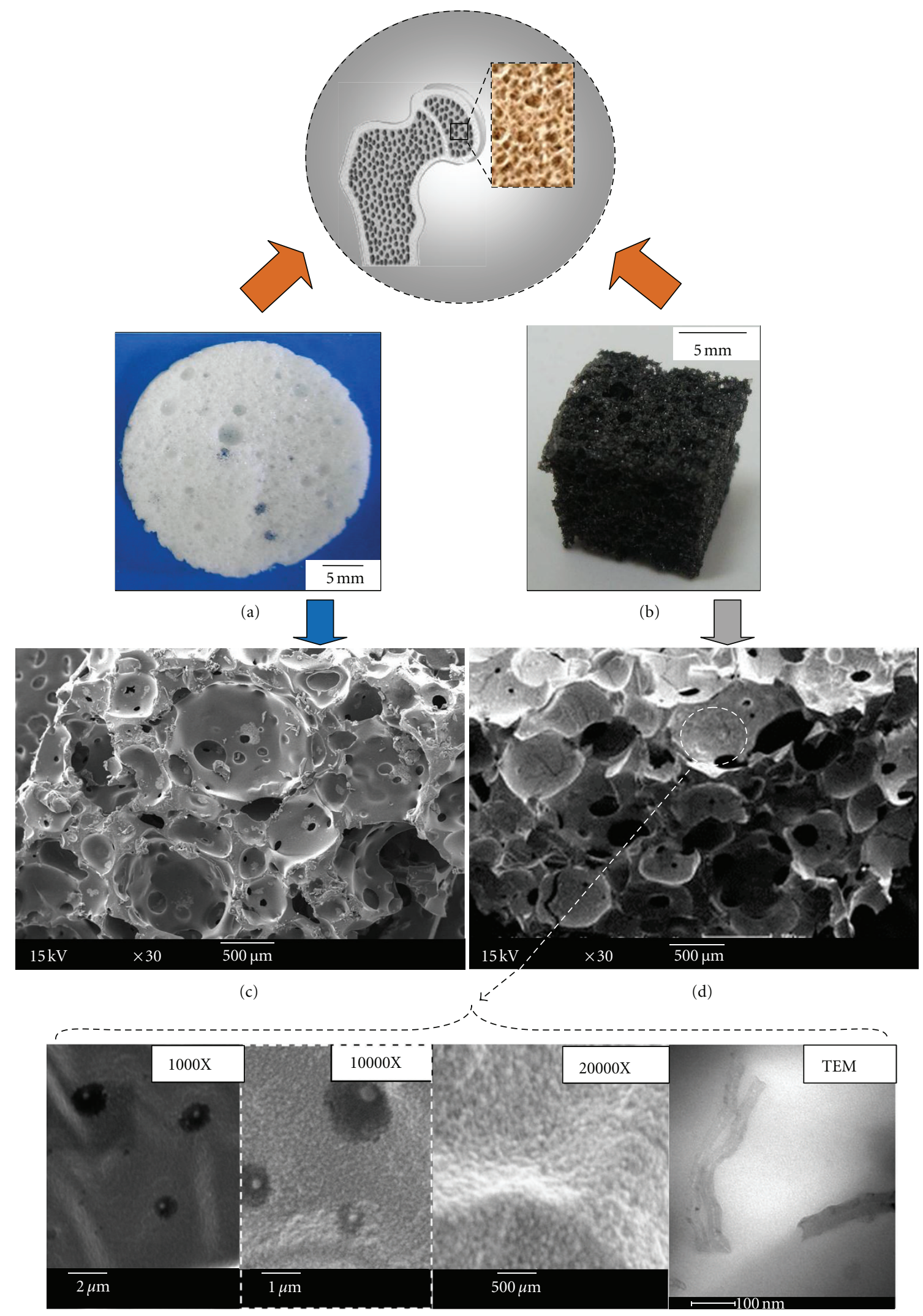

(e)

(f)

(g)

(h)

FIGURE 2: Digital (a) and SEM (c) images of porous PVA/BaG hybrid. Digital (b), SEM (d-g), and TEM (h) images of the hybrid material containing CNT-COOH. Inset (top): illustration of cancellous bone tissue macroporous structure. 

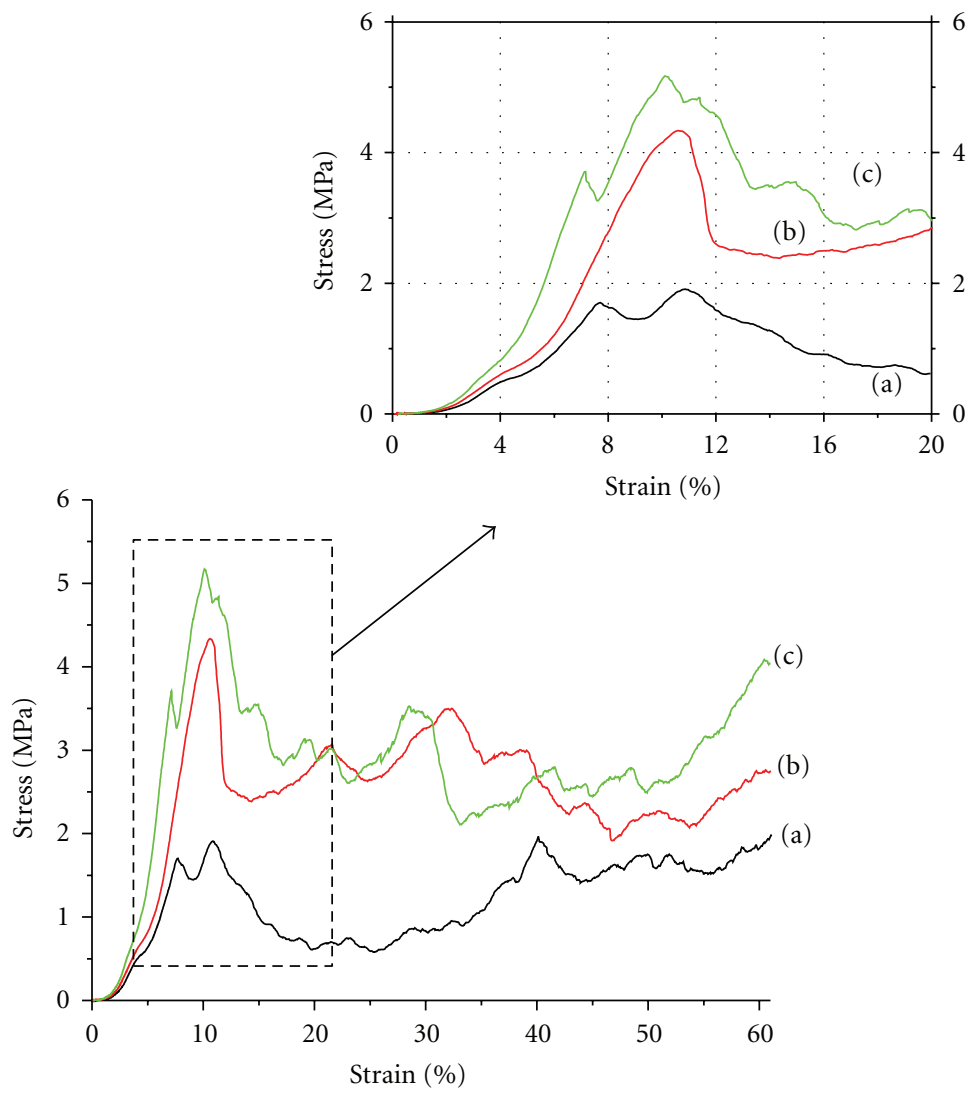

Figure 3: Stress x strain compression curves for (a) hybrid PVA/BaG; (b) hybrid cross linked with 1 wt $\%$ glutaraldehyde (PVA/BaG/GA); (c) hybrid with addition of functionalized CNT (PVA/BaG/CNT). Inset: detail of curve at initial deformation region.

magnifications (Figures 2(e), 2(f), and 2(g)) evidenced that fairly homogeneous hybrids systems were produced where no segregation or phase separation was detected. Due to the very low dimensions of carbon nanotubes (purified multiwall CNTs, with 10 to $30 \mathrm{~nm}$ external diameters) they were only detected with reasonable resolution by TEM analysis as showed in Figure 2(h).

Typical stress-strain compression curves for the three hybrid systems studied are presented in Figure 3. An increase in strength is observed when the hybrid (PVA/BaG, Figure $3(\mathrm{a})$ ) is cross linked with $1 \mathrm{wt} \%$ of glutaraldehyde (PVA/BaG/GA, Figure 3(b)). The addition of functionalized CNTs (PVA/BaG/CNT-COOH), Figure 3(c)) also led to an increase in the mechanical strength compared to the PVA/BAG hybrids, comparable to that obtained by cross linking. The average yield stress was $(2.3 \pm 0.9)$ and $(4.4 \pm$ 1.0) $\mathrm{MPa}$ for the PVA/BAG and CNT reinforced material, respectively, indicating an improvement of about $90 \%$. The yield strain (Ys) and Young's modulus (Ym) were also enhanced by approximately $30 \%$ for the $\mathrm{CNT}-\mathrm{COOH}$ hybrids as compared to not reinforced matrices (from PVA/BaG to PVA/BaG/CNT: Ys $=$ from $7.5 \pm 0.3$ to $9.6 \pm$ $1.1 \% ; \mathrm{Ym}=$ from $0.6 \pm 0.2$ to $0.8 \pm 0.3 \mathrm{MPa})$. These results indicate that the addition of functionalized CNTs were effective as a strengthening mechanism in PVA/BAG hybrids.
Concerning to tissue engineering applications, synthetic materials have to be properly designed to match the mechanical properties to be a suitable alternative for the replacement of cortical or cancellous bones. Thus, the hybrids produced in this work, PVA/BaG and hybrids reinforced with CNT, presented yield stress values within the range normally reported for trabecular bone [19]. Also, as a highly porous material and with $3 \mathrm{D}$ architecture the developed hybrid systems showed a similar trend to the trabecular bone concerning the elastic modulus.

To effectively transfer and distribute the applied load (stress), a reasonable dispersion and interface adhesion are necessary. Studies in PVA-based composites with chemically modified CNT have shown that PVA is capable of forming a crystalline coating around nanotubes, maximizing the interfacial load transfer [27-29]. This is one reason for the improved mechanical properties of hybrids when compared with pure PVA. Moreover, functionalization of CNT using $\mathrm{HNO}_{3}$ solution promotes the addition of hydrophilic moieties to the system like carboxylic, carbonyl, and phenol groups on the surface of CNTs [22]. These groups help the interaction trough hydrogen bonding between CNT and PVA molecules, both with hydrophilic character. For low concentrations of (CNT-COOH) the interaction between nanotubes is lower than their interaction with PVA 


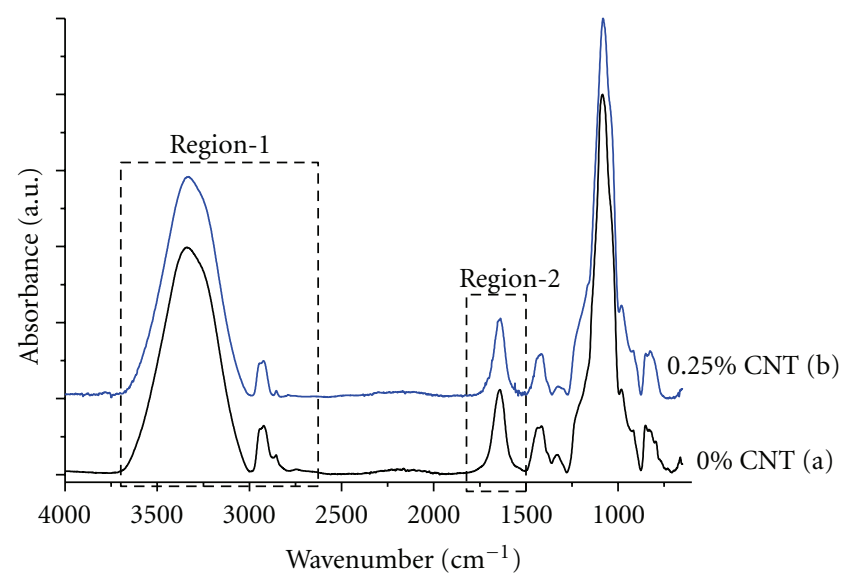

(A)
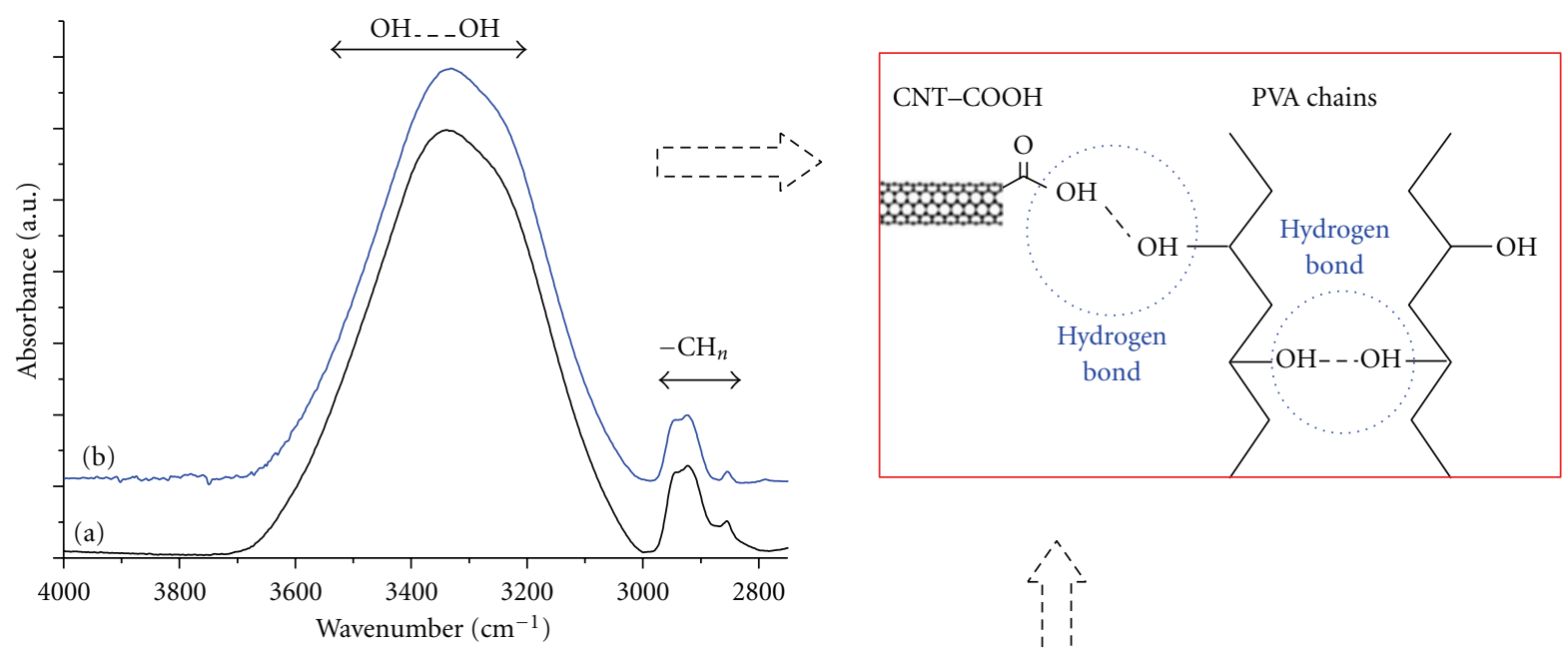

(B)

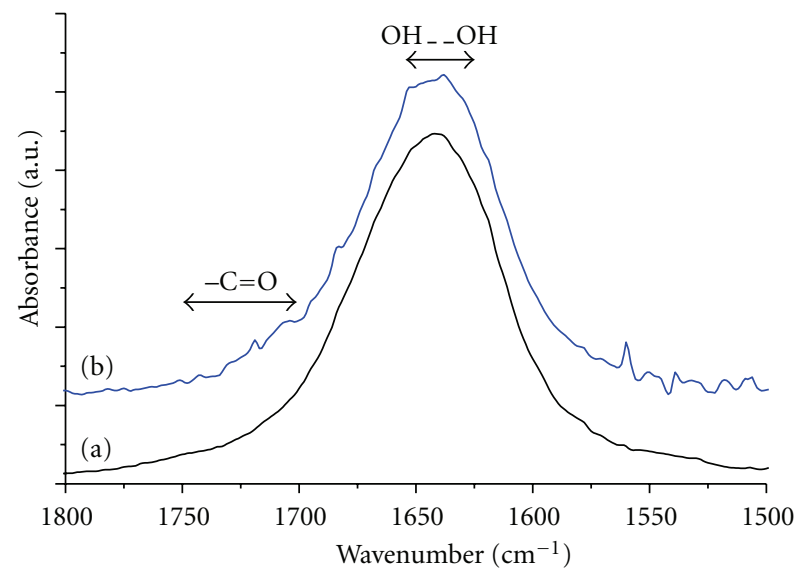

(C)

FIGURE 4: FTIR spectra of PVA/BaG (a) and PVA/BaG/CNT-COOH (b) hybrids in selected ranges of the IR spectrum: (A) $4000-600 \mathrm{~cm}^{-1}$, (B) $4000-2800 \mathrm{~cm}^{-1}$ (Region 1), and (C) $1800-1500 \mathrm{~cm}^{-1}$ (Region 2). Inset: schematic illustration of hydrogen bonds formed between hydrophilic chemical groups (hydroxyls and carboxyls). 


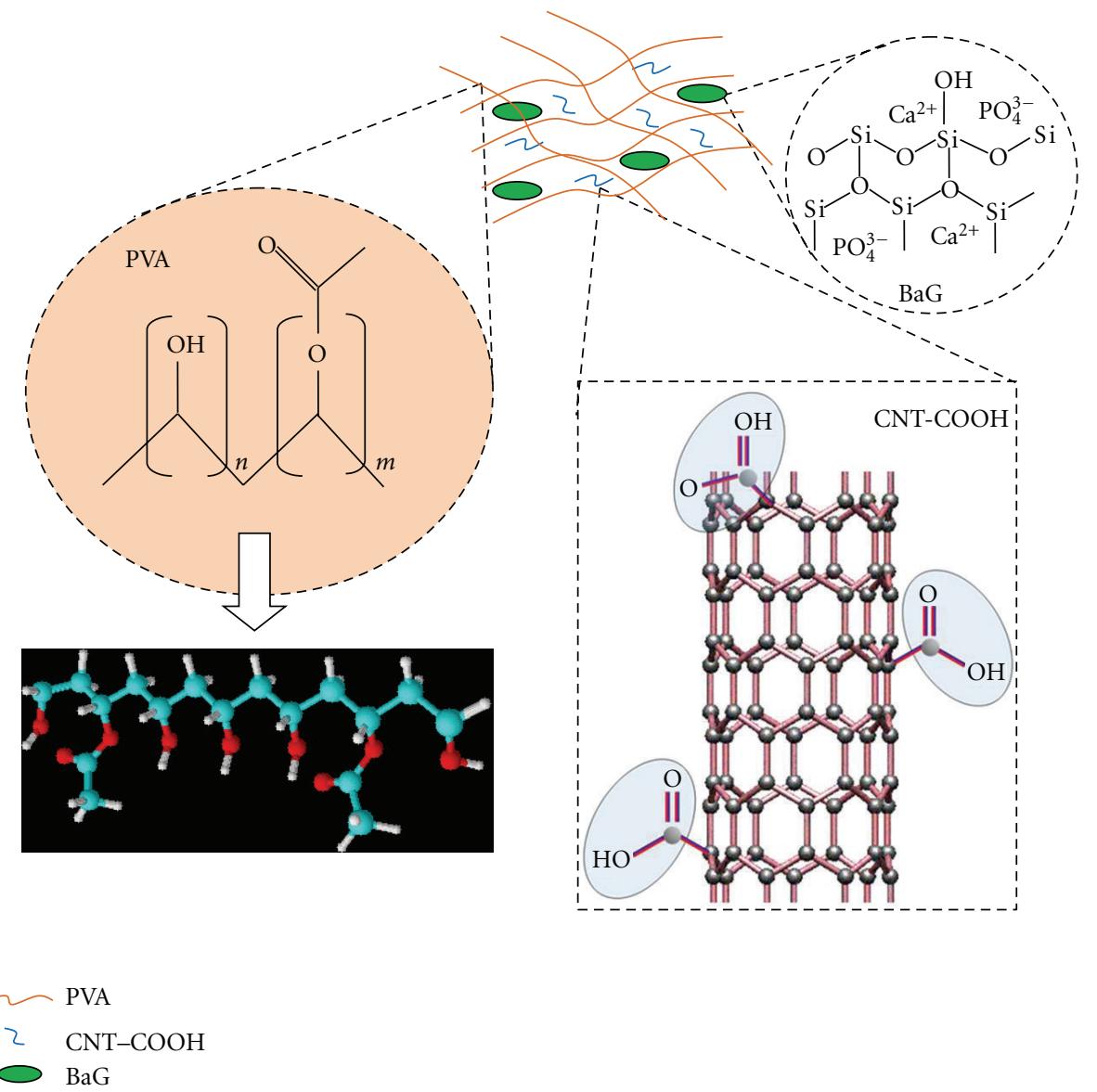

FIGURE 5: Schematic representations of the incorporation of CNT-COOH in the PVA/BaG network.

molecules, allowing their homogeneous dispersion in the PVA matrix and promotion of mechanical reinforcement of the structure [30].

As an additional supporting tool for the characterization of the hybrids, FTIR spectroscopy was performed on the samples for evaluating some of the possible interactions among chemical groups of the components of the hybrids (PVA/BaG matrices and CNTs). In Figure 4(a), it presents the typical FTIR spectra of PVA/BaG and PVA/BaG/CNT$\mathrm{COOH}$ hybrids (Figure $4(\mathrm{~A})$ (a) and (b), resp.). Both spectra are very similar with most bands associated with predominant chemical groups of the major components of the samples, PVA and $\mathrm{BaG}$, and minor contribution from CNT-COOH due to its lower content $(0.25 \mathrm{wt} \%)$. Nonetheless, based on a more in-depth analysis, focusing on some specific ranges of the FTIR spectra (Region 1 and Region 2, Figure 4(A)), it can be observed some relevant changes related to the addition of functionalized CNT in the hybrids, as presented in Figures 4(B) and 4(C). Essentially, in Figure 4(B), the vibrational bands ranging from 2800 to $3000 \mathrm{~cm}^{-1}$ can be associated with the contribution of alkyl groups $\left(\nu \mathrm{CH}_{n}\right)$ from PVA. Also, bands at $3200-3600 \mathrm{~cm}^{-1}$ are often related to hydroxyl groups (stretching, $\nu \mathrm{OH}$ ) present in CNT-COOH and PVA, with hydrogen bonds $(\mathrm{OH} \cdots \mathrm{OH})$ interactions causing some "broadening" of the region in both spectra. In addition, in Figure $4(\mathrm{C})$ (1500-1800 $\mathrm{cm}^{-1}$ ) some important contributions can be observed at 1750-1700 $\mathrm{cm}^{-1}$ from carbonyl stretching of acid modified nanotubes $(\nu \mathrm{C}=\mathrm{O}, \mathrm{CNT}-\mathrm{COOH})$ and hydrogen bonds formation (bending, $\delta(\mathrm{OH}) \mathrm{OH} \cdots \mathrm{OH}$ ) at 1650 $1630 \mathrm{~cm}^{-1}$. Thus, the results have given further evidence that hydrogen bonds were formed between hydrophilic chemical groups, such as hydroxyls and carboxyls $(-\mathrm{OH},-\mathrm{COOH})$ in the hybrids reinforced by functionalized CNT (inset Figure 4), which are expected to play a major role on the overall properties and structure of the systems produced.

In summary, the chemical modification of CNTs used in this work incorporated carboxylic groups $(-\mathrm{COOH})$, giving them a partially hydrophilic character, allowing to dispersion in aqueous media, and promoting hydrogen bonding with alcohol groups (OH, PVA) and maybe with silanols ( $\mathrm{Si}-$ $\mathrm{OH})$. Figure 5 presents a schematic representation of the interactions between carboxyl-functionalized CNT and PVA hydroxyl groups (not in scale). When prepared with bioactive glass the material will also include the interactions with silanol groups from the glass phase (Figure 5, inset $\mathrm{BaG}$ ) 
resulting in a hybrid material reinforced at the nanostructural level.

\section{Conclusions}

The chemical treatment in nitric acid led to the functionalization of CNTs with carboxylic groups. The surface modification allowed the homogeneous dispersion of CNTs in PVA solution and in the modified hybrids produced. The average yield stress of the macroporous hybrid reinforced with CNT was $(4.4 \pm 1.0) \mathrm{MPa}, 90 \%$ higher than the reference hybrid material PVA/BAG. Yield strain and Young's modulus were enhanced in about $30 \%$ for the CNT$\mathrm{COOH}$ hybrids. These values are in agreement with those values reported in the literature for potential application in repairing cancellous bone tissue. In summary, this study has offered a new approach for designing engineered synthetic hybrids aiming at developing nanostructured systems with equivalent mechanical properties of bone tissues.

\section{Acknowledgments}

This research was funded by FAPEMIG/CAPES/CNPq Brazilian Agencies. The authors thank the Staff of the Center of Microscopy/UFMG for TEM/SEM analyses.

\section{References}

[1] A. J. Salgado, O. P. Coutinho, and R. L. Reis, "Bone tissue engineering: state of the art and future trends," Macromolecular Bioscience, vol. 4, no. 8, pp. 743-765, 2004.

[2] Q. Chen, J. A. Roether, and A. R. Boccaccini, Topics in Tissue Engineering, BTE group, 2008.

[3] K. J. L. Burg, S. Porter, and J. F. Kellam, "Biomaterial developments for bone tissue engineering," Biomaterials, vol. 21, no. 23, pp. 2347-2359, 2000.

[4] V. Olivier, N. Faucheux, and P. Hardouin, "Biomaterial challenges and approaches to stem cell use in bone reconstructive surgery," Drug Discovery Today, vol. 9, no. 18, pp. 803-811, 2004.

[5] J. J. Blaker, V. Maquet, R. Jérôme, A. R. Boccaccini, and S. N. Nazhat, "Mechanical properties of highly porous PDLLA/ Bioglass composite foams as scaffolds for bone tissue engineering," Acta Biomaterialia, vol. 1, no. 6, pp. 643-652, 2005.

[6] D. W. Hutmacher, J. T. Schantz, C. X. Lam, K. C. Tan, and T. C. Lim, "State of the art and future directions of scaffold-based bone engineering from a biomaterials perspective," Journal of Tissue Engineering and Regenerative Medicine, vol. 1, no. 4, pp. 245-260, 2007.

[7] J. R. Jones, "New trends in bioactive scaffolds: the importance of nanostructure," Journal of the European Ceramic Society, vol. 29, no. 7, pp. 1275-1281, 2009.

[8] P. Fabbria, V. Cannillo, A. Sola, A. Dorigato, and F. Chiellini, "Highly porous polycaprolactone-45S5 Bioglass scaffolds for bone tissue engineering," Composites Science and Technology, vol. 70, no. 13, pp. 1869-1878, 2010.

[9] L. C. Gerhardt and A. R. Boccaccini, "Bioactive glass and glassceramic scaffolds for bone tissue engineering," Materials, vol. 3, no. 7, pp. 3867-3910, 2010.
[10] J. J. Blaker, S. N. Nazhat, V. Maquet, and A. R. Boccaccini, "Long-term in vitro degradation of PDLLA/Bioglass bone scaffolds in acellular simulated body fluid," Acta Biomaterialia, vol. 7, no. 2, pp. 829-840, 2011.

[11] Y. Minaberry and M. Jobbágy, "Macroporous bioglass scaffolds prepared by coupling sol-gel with freeze drying," Chemistry of Materials, vol. 23, pp. 2327-2332, 2000.

[12] M. M. Pereira, J. R. Jones, and L. L. Hench, "Bioactive glass and hybrid scaffolds prepared by sol-gel method for bone tissue engineering," Advances in Applied Ceramics, vol. 104, no. 1, pp. 35-42, 2005.

[13] G. Andrade, E. F. Barbosa-Stancioli, A. A. Piscitelli Mansur, W. L. Vasconcelos, and H. S. Mansur, "Design of novel hybrid organic-inorganic nanostructured biomaterials for immunoassay applications," Biomedical Materials, vol. 1, no. 4, article 008, pp. 221-234, 2006.

[14] H. S. Mansur and H. S. Costa, "Nanostructured poly (vinyl alcohol)/bioactive glass and poly(vinyl alcohol)/chitosan/bioactive glass hybrid scaffolds for biomedical applications," Chemical Engineering Journal, vol. 137, no. 1, pp. 72-83, 2008.

[15] H. S. Costa, M. F. Rocha, G. I. Andrade et al., "Sol-gel derived composite from bioactive glass-polyvinyl alcohol," Journal of Materials Science, vol. 43, no. 2, pp. 494-502, 2008.

[16] A. A. R. De Oliveira, V. Ciminelli, M. S. S. Dantas, H. S. Mansur, and M. M. Pereira, "Acid character control of bioactive glass/polyvinyl alcohol hybrid foams produced by solgel," Journal of Sol-Gel Science and Technology, vol. 47, no. 3, pp. 335-346, 2008.

[17] H. S. Costa, E. F. B. Stancioli, M. M. Pereira, R. L. Oréfice, and H. S. Mansur, "Synthesis, neutralization and blocking procedures of organic/inorganic hybrid scaffolds for bone tissue engineering applications," Journal of Materials Science, vol. 20, no. 2, pp. 529-535, 2009.

[18] H. S. Costa, A. A. P. Mansur, M. M. Pereira, and H. S. Mansur, "Engineered hybrid scaffolds of poly(vinyl alcohol)/bioactive glass for potential bone engineering applications: synthesis, characterization, cytocompatibility, and degradation," Journal of Nanomaterials, vol. 2012, Article ID 718470, 16 pages, 2012.

[19] H. S. Mansur, H. S. Costa, A. A. P. Mansur, and M. M. Pereira, "3D-macroporous hybrid scaffolds for tissue engineering: network design and mathematical modeling of the degradation kinetics," Materials Science and Engineering, vol. 32, p. 404, 2012.

[20] M. K. Amal, E. Mahmoud, and M. Farag, "Carbon nanotube reinforced composites: potential and current challenges," Materials and Design, vol. 28, no. 9, pp. 2394-2401, 2007.

[21] H. Park, J. Zhao, and J. P. Lu, "Effects of sidewall functionalization on conducting properties of single wall carbon nanotubes," Nano Letters, vol. 6, no. 5, pp. 916-919, 2006.

[22] J. Liu, A. G. Rinzler, H. Dai et al., "Fullerene pipes," Science, vol. 280, no. 5367, pp. 1253-1256, 1998.

[23] X. Zhang, T. V. Sreekumar, T. Liu, and S. Kumar, "Properties and structure of nitric acid oxidized single wall carbon nanotube films," Journal of Physical Chemistry B, vol. 108, no. 42, pp. 16435-16440, 2004.

[24] W. Song, Z. Zheng, W. Tang, and X. Wang, "A facile approach to covalently functionalized carbon nanotubes with biocompatible polymer," Polymer, vol. 48, no. 13, pp. 3658-3663, 2007.

[25] P. Petrov, G. Georgiev, D. Momekova, G. Momekov, and C. B. Tsvetanov, "UV-assisted grafting of polymers: a method towards biocompatible carbon nanotubes," Polymer, vol. 51, no. 12, pp. 2465-2471, 2010. 
[26] G. S. Nanda, R. Saravendra, W. C. Jae, L. A. Lin, and H. C. Siew, "Polymer nanocomposites based on functionalized carbon nanotubes," Progress in Polymer Science, vol. 35, p. 837, 2010.

[27] J. N. Coleman, M. Cadek, K. P. Ryan et al., "Reinforcement of polymers with carbon nanotubes. The role of an ordered polymer interfacial region. Experiment and modeling," Polymer, vol. 47, no. 26, pp. 8556-8561, 2006.

[28] J. N. Coleman, U. Khan, W. J. Blau, and Y. K. Gun'ko, “Small but strong: a review of the mechanical properties of carbon nanotube-polymer composites," Carbon, vol. 44, no. 9, pp. 1624-1652, 2006.

[29] K. P. Ryan, M. Cadek, V. Nicolosi et al., "Carbon nanotubes for reinforcement of plastics? A case study with poly(vinyl alcohol)," Composites Science and Technology, vol. 67, no. 7-8, pp. 1640-1649, 2007.

[30] Z. T. D. Spitalskya, K. Papagelis, and C. Galiotis, "Carbon nanotube-polymer composites: chemistry, processing, mechanical and electrical properties," Progress in Polymer Science, vol. 35 , no. 3, pp. 357-401, 2010. 

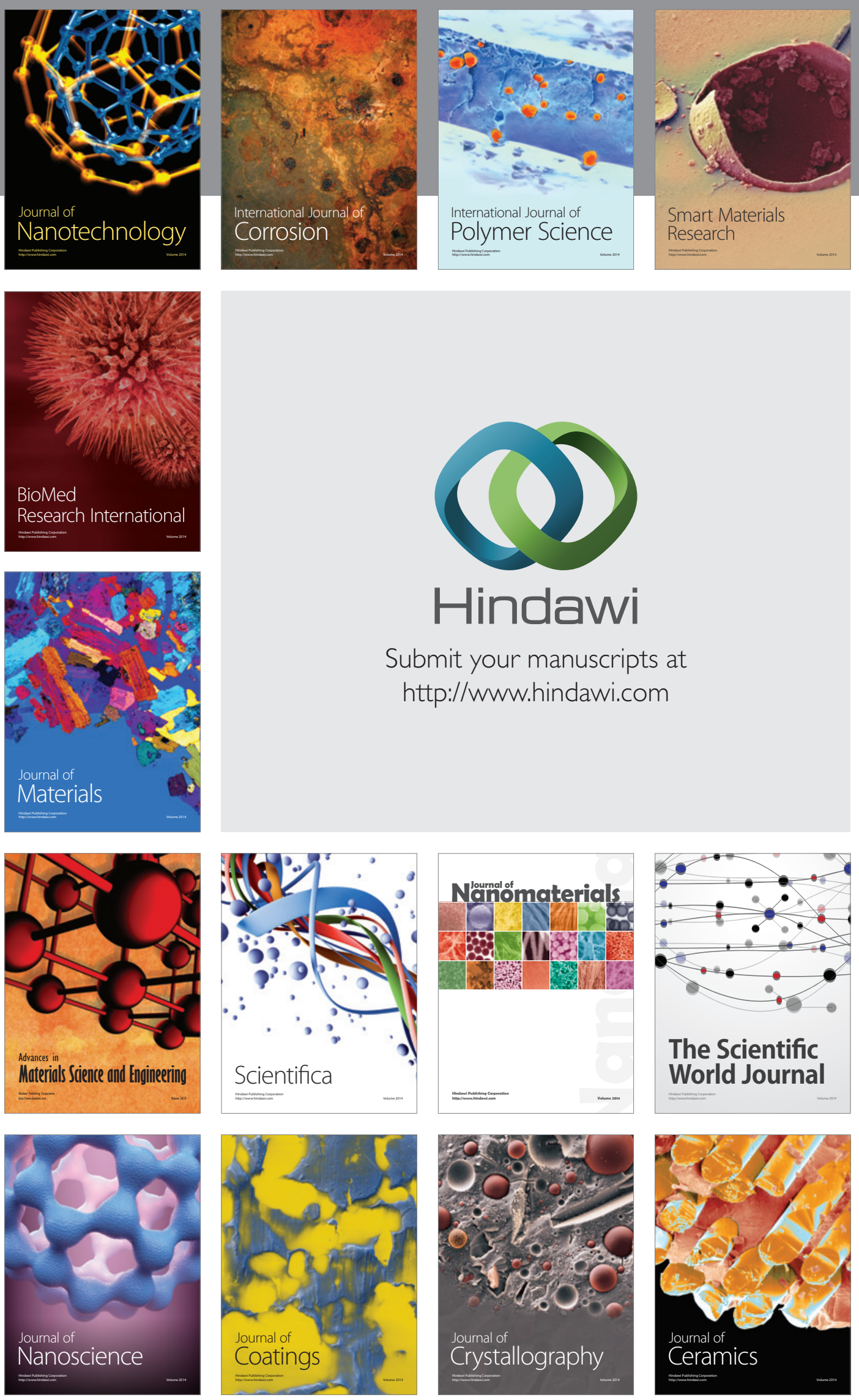

The Scientific World Journal

Submit your manuscripts at

http://www.hindawi.com

\section{World Journal}

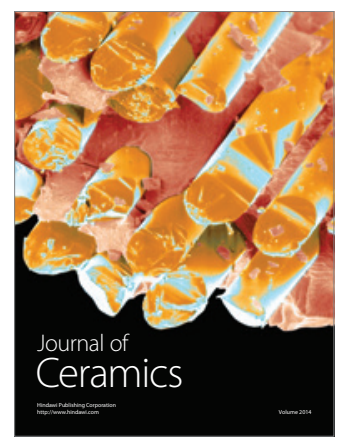

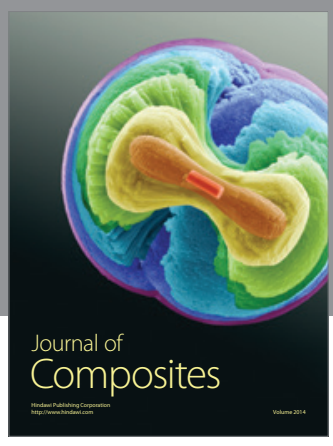
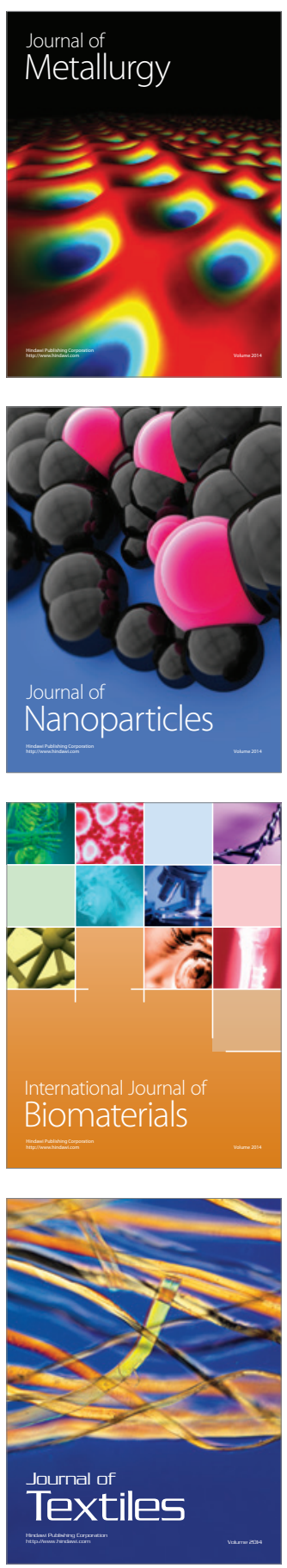